\title{
LOS LIBERALES RADICALES INGLESES Y LA FILOSOFÍA POLÍTICA DE FRANCISCO SUÁREZ ${ }^{1}$
}

\author{
English Liberal Radicals and Francisco \\ Suarez's Political Philosophy.
}

ALFONSO DÍAZ VERA ${ }^{2}$

Fecha de recepción: 18 de junio de 2018

Fecha de aceptación: 7 de mayo de 2019

Resumen: El teólogo y padre jesuita Francisco Suárez ejerció una notable influencia intelectual en la convulsa Inglaterra del siglo XVII. Su filosofía política, fundamentada en los conceptos y principios clásicos y cristianos sobre la comunidad, contrasta en este aspecto con la de los contractualistas sociales, pero a la vez aporta, mucho antes que éstos, una teoría del gobierno de corte democrático. El liberalismo inglés de finales del siglo XIX vivirá, al igual que en Alemania, un intenso debate entre quienes, como los radicales, ponían el énfasis en los principios y quienes apoyaban una políica condicionada a las necesidades del momento. Aún en el marco de esa disputa, cuando a principios del siglo XX el nuevo liberalismo comenzaba a imponerse, un grupo de intelectuales católicos ingleses reivindicó la figura de Francisco Suárez. Determinados elementos de su teoría, como el énfasis en el componente moral de las relaciones políticas o las limitaciones a las competencias del cuerpo de gobierno de la comunidad, estaban en consonancia con los ideales liberales radicales, que

${ }^{1}$ Este trabajo es resultado del proyecto "Sociedad, política y economía: proyecciones de la Escolástica española en el pensamiento británico y anglosajón" (Programa Estatal de Fomento de la Investigación Científica y Técnica de Excelencia, referencia: FFI2017-84435-P) financiado por la Agencia Española de Investigación (AEI) y el Fondo Europeo de Desarrollo Regional (FEDER).

2 Doctorando del programa de CC. Sociales y Jurídicas de la Universidad Rey Juan Carlos. Máster Universitario en Humanidades por la Universidad Francisco de Vitoria. Licenciado en CC. Económicas por la Universidad de Alicante. Email: a.diazve.2016@alumnos.urjc.es.

Procesos de Mercado: Revista Europea de Economía Política Vol. XVI, n. ${ }^{\circ}$ 1, Primavera 2019, pp. 141 a 175 
fueron superados por la expansión y el aumento de poder y funciones de los Estados.

Palabras clave: Radicalismo, William Cobbett, Hilaire Belloc, Francisco Suárez, Liberalismo decimonónico.

Clasificación JEL: A13, B15, B25, N13, Z13.

Abstract: The theologian and Jesuit Priest Francisco Suárez had a remarkable intellectual influence in the turbulent England of the seventeenth century. His political philosophy, based on Classical and Christian concepts and principles on the community, contrasts in this respect with that of social contractarians, like Hobbes, Locke or Rousseau, but at the same time it contributes, much earlier than these, to a theory of democratic government. The English liberalism of the late nineteenth century saw, like in Germany, a controversy between those who, like the Radicals, put the emphasis on the principles and moral values and those who supported a practical policy conditioned to the needs of the moment. In the context of this dispute, when at the beginning of the 20th century the new liberalism began to prevail, a group of English Catholic intellectuals claimed the figure of Francisco Suárez. Certain elements of his theory, such as the emphasis on the moral component of political relations or limitations on the competencies of the governing body of the community, were in line with radical liberal ideals, which were overcome by the expansion and increase of power and functions of the States.

Keywords: Radicalism, William Cobbett, Hilaire Belloc, Francisco Suárez, XIX Century Liberalism.

JEL classification: A13, B15, B25, N13, Z13.

"La sociedad es como el aire, necesario para respirar, pero insuficiente para vivir del mismo"

GEORGE SANTAYANA

\section{I \\ INTRODUCCIÓN}

Los últimos años del siglo XIX supusieron para el liberalismo inglés un periodo de fuertes disputas internas que, si bien no trajo 
consigo las escisiones políticas que caracterizaron a sus correligionarios alemanes, marcó un punto de ruptura respecto de lo que había sido hasta entonces la tradición liberal en Inglaterra. Los bandos en disputa, al igual que en el caso alemán, podrían caracterizarse en líneas generales en función de su apuesta por la primacía de los valores liberales tradicionales o por el interés político, económico y militar de su país en el marco de la lucha por la hegemonía europea y mundial de las grandes potencias. En ambos casos, la segunda cuestión resultó prioritaria, dando lugar en Inglaterra a las reformas sociales de Asquith, primer ministro liberal entre 1908 y 1916, similares a las llevadas a cabo por Bismarck en Alemania tres décadas antes.

Previamente a este periodo, el pensamiento liberal inglés se caracterizó por la multiplicidad y variedad ideológica de sus distintas corrientes. La compleja multiplicidad de movimientos políticos e intelectuales que se dieron en la Inglaterra de finales del siglo XVIII y principios del XIX se formó sobre la base de dos factores fundamentales: las ideas sobre el gobierno, influenciados a su vez por las confrontaciones políticas y religiosas que habían marcado la historia del país en los dos siglos anteriores; y los profundos cambios socio-económicos que protagonizaron todo el periodo que va de la primera a la segunda revolución industrial.

Dos acontecimientos extra-insulares, pero no lejanos en cuanto a su importancia en el devenir histórico del país, las revoluciones americana y francesa, supusieron un desafío que puso a prueba las bases filosóficas y políticas sobre las que se asentaba la vida en comunidad en el país. En contra de lo que suele pensarse, la sociedad inglesa no cerró unánimemente filas en torno al general Cornwallis o el filósofo Burke. Figuras como Thomas Paine, Charles James Fox o Joseph Priestley pusieron sus ideas radicales ${ }^{3}$ por delante de su fidelidad al rey ${ }^{4}$ y a la nación.

3 Principalmente exigían reformas democráticas del sistema de gobierno, como la extensión del sufragio, en aras de una mayor representación.

4 En opinión de G.K. Chesterton Inglaterra no era una monarquía al menos desde la denominada Revolución Gloriosa (1688), sino que estaba gobernada por una oligarquía terrateniente con fuertes intereses económicos y comerciales, de modo que, respecto de la rebelión de las colonias americanas, comenta: "The Americans were defying George the Third, under the extraordinary idea that George the Third ruled 
Los liberales radicales ${ }^{5}$, si bien compartían la necesidad de profundas reformas democráticas, no constituían un grupo homogéneo. Figuras como John Bright o Richard Cobden centraron sus reivindicaciones libertarias en la eliminación de aranceles y el fomento del comercio internacional. Más singular resultó el personaje de William Cobbett. De alma profundamente inglesa, Cobbett se mostró contrario a los procesos revolucionarios de América y Francia, pero no por ello dejó de reivindicar los principios liberales, en especial en el ámbito agrario. Cobbett relacionó la situación económica y social del campesinado inglés con las reformas agrarias que, desde tiempo de Enrique VIII, habían favorecido a un pequeño grupo de terratenientes influyentes promotores del cisma de la Iglesia en Inglaterra. En tiempos de Cobbett, los intereses de esa clase se identificaban con la política del sector whig. Al perder los campesinos sus derechos sobre la tierra, habrían sufrido también una notable merma en sus libertades civiles.

Un siglo después, estas ideas fueron desarrolladas de manera sistemática por Hilaire Belloc, que junto con G.K. Chesterton sería considerado el padre de la teoría económica y política conocida como distributismo ${ }^{6}$. También se puede adscribir a esta línea de pensamiento al hermano de Gilbert Keith, Cecil Chesterton, que procedía de las filas del socialismo fabiano ${ }^{7}$. Al igual que el movimiento cartista ${ }^{8}$, los fabianos encontraron inspiración en algunas de las ideas más libertarias y democráticas de los radicales.

England. When they set up their republic, the simple colonists probably really did think that England was a monarchy. The same illusion filled the English Whigs; but it was only because England had once been a monarchy." (Chesterton, 1910, 8).

5 El término "radical" se acuñó a partir de la exigencia por parte de Charles James Fox en el Parlamento inglés de una "reforma radical" del sistema electoral en 1797.

${ }^{6}$ Línea de pensamiento que, basándose en la Doctrina Social de la Iglesia y en particular en la encíclica Rerum Novarum, considera que la propiedad privada de los medios de producción debería estar ampliamente distribuida entre la población.

7 Denominados así por su empleo, en lugar de la acción directa, de la táctica dilatoria para desgastar al "enemigo", como hiciera el general romano Quinto Fabio Máximo en su lucha contra Aníbal.

${ }^{8}$ Movimiento obrero que se desarrolló en la Gran Bretaña de mediados del siglo XIX, con objetivos como las mejora de las condiciones de trabajo o la extensión del sufragio. 
El presente trabajo trata de analizar la posible influencia del jesuita español Francisco Suárez en los desarrollos intelectuales de los autores ingleses señalados. Del mismo modo que está estudiada ${ }^{9}$, tal vez incluso sobrevalorada, la influencia de la filosofía política del Doctor Eximio en el entorno iberoamericano, consideramos interesante incidir en el análisis del efecto de las tempranamente modernas teorías respecto del gobierno de la comunidad de Francisco Suárez en el ámbito inglés que, aunque culturalmente más lejano, destaca por su capacidad para generar ideas originales e influyentes.

Nuestro análisis partirá de una descripción general del ideario radical, en comparación con otras tendencias dentro del liberalismo inglés del XIX. A continuación describiremos sucintamente algunos rasgos de la filosofía política de Francisco Suárez que pudieran a nuestro juicio confluir con dicho ideario, para después analizar la controvertida recepción del teólogo granadino en la Inglaterra del XVII y su aparente "olvido" apenas un siglo después. Veremos por último como la figura de Suárez fue rescatada de su abandono y reivindicada por autores católicos ingleses influidos a su vez por las ideas de los liberales radicales. La filosofía de Suárez combina dos elementos fundamentales que están presentes en el espíritu del radicalismo inglés: un acercamiento de corte tradicional y moralista a la cuestión política y una teoría del gobierno de corte democrático.

\section{II}

\section{LOS RADICALES Y LA TRADICIÓN LIBERAL}

En 1897, Hilaire Belloc ${ }^{10}$ publicaría, junto con otros cinco destacados estudiantes liberales de Oxford, el volumen Essays in Liberalism

9 Cabe destacar, en este sentido, las discusiones dentro de la historiografía argentina del siglo XX, entre quienes niegan y afirman la influencia de Suárez en el movimiento independentista, en virtud sobre todo del matiz secularista o religioso que pretendan dar al mismo (Bosca, 2009, 201).

10 Hilaire Belloc (1870-1953), escritor, periodista e historiador inglés de origen francés. Escribió el ensayo "The Liberal Tradition" poco después de graduarse con honores en historia en Oxford, donde había destacado como orador y presidente de la Oxford Union. 
by Six Oxford $\mathrm{Men}^{11}$, dedicado a John Morley. Entre sus compañeros se encontraban el historiador económico J.L. Hammond, el político J.A. Simon y el editor de The Economist, F.W. Hirst. El ensayo con el que Belloc contribuía a este volumen se denominaba "The Liberal Tradition", y venía a constituir una excelente descripción de la encrucijada ideológica en la que se encontraba el liberalismo inglés en aquel momento. En este ensayo Belloc pone de manifiesto su temor por el grave peligro de abandono del ideal cívico del Partido Liberal en un intento por parte de sus dirigentes de sobreponerse a la derrota electoral del año anterior ${ }^{12}$. Para Belloc las bases del verdadero liberalismo inglés son las asentadas por líderes como Fox, Cobbett y Bright, es decir, las que caracterizaron desde finales del siglo XVIII y durante todo el XIX el movimiento radical.

Con carácter general, los liberales radicales simpatizaron con el espíritu de las revoluciones americana y francesa. A Charles James Fox (1749-1806), su simpatía por la segunda le costó su amistad con Edmund Burke, cuya pérdida lamentó profundamente ${ }^{13}$. Semejante postura política le acarreó además la enemistad y animadversión de muchos otros de sus compatriotas. Su experiencia fue, en este sentido, parecida la tatarabuelo de Hilaire Belloc, el científico Joseph Priestley, "descubridor" del oxígeno y también destacado pensador radical, quien tras la publicación en 1791 de su crítica a Reflexiones sobre la revolución francesa de Burke vio como una turba asaltaba su casa en Birmingham ${ }^{14}$.

Fox era hijo de Lord Holland, general y político whig. Sus padres admiraban a Rousseau y le criaron con condescendencia. En la década de 1780 lideraba el ala radical de los liberales ingleses, que "empezaron a flirtear con una justificación potencialmente democrática de gobierno que empezaba por el derecho del pueblo a elegir o cambiar a sus gobernantes. Además se decía que ese derecho tenía sus raíces no solo en la naturaleza sino también en la historia." 15 Desde ese punto de vista, todos los gobiernos tenían su origen la

\footnotetext{
11 Belloc (1897)

12 Mc Carthy $(1978,19)$

13 Schama $(2005,56)$

14 Pearce $(2015,4)$

15 Schama (2005, 44).
} 
aceptación voluntaria por parte del pueblo. Dicha aceptación había de ser entendida como un contrato mutuo: autoridad a sus representantes a cambio de la protección de su libertad y seguridad.

Dentro del liberalismo radical del siglo XIX destacaron los impulsores de la denominada Escuela de Manchester: Richard Cobden (1804-1865) y John Bright (1811-1889). Ambos fueron firmes partidarios del libre comercio y contrarios a las políticas imperialistas. Cobden concebía el mundo desde el ideal una comunidad humana indivisible de cultivadores, fabricantes y tenderos, donde las guerras serían reemplazadas por la competitividad comercial. Tanto él como Bright fueron considerados por Gladstone, junto con él mismo, como los legítimos representantes de la Gran Bretaña auténticamente moral ${ }^{16}$, frente al oportunismo de sus rivales políticos. Posteriormente el propio Gladstone desataría las iras anti-imperialistas de Bright por su política en Egipto. John Bright fue diputado liberal en numerosas ocasiones, destacando por su oposición a toda ley que tratase de limitar la libertad individual o el libre comercio. Particularmente famosa fue su oposición a las proteccionistas leyes de los cereales (Corn Laws). Su hermano Jacob fue uno de los primeros partidarios del sufragio femenino en la década de 1860, junto con John Stuart Mill.

Si Gladstone, Cobden y Bright se consideraban representantes de la Gran Bretaña auténtica, la personificación del concepto de la Inglaterra tradicional o "Little England" era William Cobbett (17631835). Cobbett encarnaba todo lo rural, aunque dirigía su llamamiento hacia las ciudades. Político, agricultor y periodista, empleó su influencia con el ánimo de socavar los privilegios de los terratenientes absentistas y mejorar las condiciones de vida del campesinado inglés. Tomó parte activa en las reformas radicales que caracterizaron la tercera década del siglo XIX, como la emancipación de los católicos (1829), la derogación de la esclavitud en las colonias (1833), y, sobre todo, la Reform Bill de 1832, que supuso la revitalización de la Cámara de los Comunes, la ampliación del censo en medio millón de británicos y la eliminación de sus odiados Rotten Boroughs ${ }^{17}$.

\footnotetext{
16 Ibid, p. 331.

17 Distritos electorales despoblados que mantenían su representación.
} 
III

\section{LAS DOS ALMAS DEL LIBERALISMO INGLÉS}

Cuando Belloc escribe "The Liberal Tradition" el Partido Liberal se hallaba en una encrucijada, no sólo por la reciente derrota electoral, sino ante todo por la división interna entre dos corrientes radicalmente opuestas dentro del partido. Muchos vieron en la segunda la causa de la primera. Los sucesivos intentos de Gladstone de sacar adelante el proyecto del Home Rule para Irlanda habían provocado el descontento del ala whig del partido, tradicional representante de los intereses de los terratenientes, y de otros elementos más moderados dentro del liberalismo, con un fuerte componente unionista, que fueron derivando hacia posiciones más conservadoras. Junto a éstos, algunos liberales, liderados por Lord Rosebery, comenzaban a abrazar la causa del imperialismo ${ }^{18}$.

Por el contrario, los llamados "radicales", entre cuyas filas se hallaban políticos como John Bright, Henry Labouchere o John Morley, se aferraban a los tradicionales principios de la libertad individual, el comercio libre, la restricción del poder de la Cámara de los Lores o el autogobierno local.

Esta dualidad estuvo presente desde los inicios del Partido Liberal, que había surgido como una alianza casi "contra natura" de whigs, radicales y peelitas ${ }^{19}$. Previamente, las diversas corrientes dentro del liberalismo inglés habían pactado para promover e impulsar las intensas reformas políticas que caracterizaron los reinados de Jorge IV y Guillermo IV.

El punto de división entre ambos tipos de liberales es, para Belloc, la conservación del elemento básico de los liberales que llevaron a cabo la revolución política en Inglaterra: un determinado "ideal cívico" 20 . Dicho ideal se hallaría en peligro tras los intentos de una parte del partido de adaptarse a la nueva situación económica y política del país. Los políticos liberales que, a lo largo del siglo XIX, ampliaron el censo, otorgaron más autonomía a los

\footnotetext{
18 Mc Carthy $(1978,22)$

19 Facción disidente de los tories liderada por Robert Peel, defensores a ultranza del libre comercio.

20 Belloc $(1897,1)$.
} 
territorios y se opusieron a las leyes que aumentaban los privilegios de una minoría, tenían en mente, como base de una sociedad sana, un "ciudadano ideal" que fuera responsable, consciente, independiente del control de otros y con la fuerza moral que le hiciera inmune a intentos de abuso por parte de hombres más poderosos. Así sería el ideal de liberales ilustres como los citados por Belloc en su ensayo: Charles James Fox, William Cobbett, John Bright, y, en alguna medida, también de Richard Cobden ${ }^{21}$.

Podemos agrupar las diferencias entre las dos tendencias dentro del liberalismo inglés del XIX en la siguiente tabla:

TABLA 1: LAS DOS TENDENCIAS DEL LIBERALISMO INGLÉS

\begin{tabular}{ccc}
\hline Tema: & Radicales & Otras corrientes liberales $^{22}$ \\
\hline Imperialismo & $\begin{array}{c}\text { Partidarios de la autonomía de } \\
\text { los territorios y contrarios a la } \\
\text { expansión del Imperio. Simpatía } \\
\text { hacia las revoluciones europeas } \\
\text { y la autonomía local. }\end{array}$ & $\begin{array}{c}\text { Partidarios del } \\
\text { mantenimiento y expansión } \\
\text { de los dominios imperiales. } \\
\text { Contrarios al Home Rule }\end{array}$ \\
\hline & $\begin{array}{c}\text { Contrarios a toda intervención } \\
\text { que superase el principio de } \\
\text { auto-gobierno. Limitación del } \\
\text { tamaño del estado y del ejército, } \\
\text { así como del nivel de exacción de } \\
\text { impuestos. }\end{array}$ & $\begin{array}{c}\text { Partidarios de un estado } \\
\text { imperiales y de un ejército } \\
\text { fuerte en tiempos de paz. }\end{array}$ \\
\hline $\begin{array}{c}\text { Libertad } \\
\text { individual }\end{array}$ & $\begin{array}{c}\text { Contrarios a toda restricción } \\
\text { arbitraria de libertades } \\
\text { individuales. }\end{array}$ & $\begin{array}{c}\text { Supeditada al mantenimiento } \\
\text { del orden. }\end{array}$ \\
\hline
\end{tabular}

${ }^{21}$ Ibid, pp. 8-9

22 Incluiría diversos sectores del liberalismo inglés, como los tradicionales "whigs", facción que se configuró en la lucha contra los privilegios de la Corona y el catolicismo y que representó los intereses de la oligarquía terrateniente; los peelitas, disidentes de las filas conservadoras por su deriva proteccionista; o los "nuevos liberales" o "liberales-imperialistas" que, en tiempo de Belloc, se mostraron partidarios del Imperio y de un estado fuerte y propusieron, en ciertos casos, la imposición de aranceles.

${ }^{23}$ El Home Rule, concesión de autonomía limitada para Irlanda, fue un asunto crucial para el Partido Liberal inglés. Los intentos de implementación del Home Rule por sucesivos gobiernos de Gladstone desgastaron las filas liberales.

${ }^{24}$ Partidarios de la emancipación de los católicos y contrarios al Poor Act, Licensing Laws y otras medidas restrictivas. 


\begin{tabular}{lcc}
\hline Libre comercio & $\begin{array}{c}\text { Como principio universal, por } \\
\text { aversión a toda limitación estatal } \\
\text { en la libertad de acción de los } \\
\text { particulares. }\end{array}$ & $\begin{array}{c}\text { Como herramienta para el } \\
\text { desarrollo de la economía y el } \\
\text { imperio, mediante } \\
\text { eliminación de trabas a la } \\
\text { importación de alimentos y } \\
\text { materias primas y }\end{array}$ \\
$\begin{array}{l}\text { Cumplimiento } \\
\text { de contratos }\end{array}$ & $\begin{array}{c}\text { Como cuestión de honor de los } \\
\text { particulares, y consecuencia de } \\
\text { las convicciones morales del } \\
\text { ciudadano ideal. }\end{array}$ & $\begin{array}{c}\text { El estado debería garantizarlo } \\
\text { para promover la seguridad } \\
\text { jurídica necesaria para los } \\
\text { negocios. }\end{array}$ \\
\hline Extensión del \\
sufragio & $\begin{array}{c}\text { Partidarios de la extensión del } \\
\text { sufragio censitario, basada en el } \\
\text { aumento del número de }\end{array}$ & $\begin{array}{c}\text { En función de las necesidades } \\
\text { del momento. }\end{array}$ \\
\hline personas responsables y libres. & Contrarios a todo privilegio, no \\
Privilegios & aceptando justificaciones & $\begin{array}{c}\text { Defensa de intereses } \\
\text { oligárquicos y no }\end{array}$ \\
& históricas para los mismos. & $\begin{array}{c}\text { cuestionamiento de } \\
\text { privilegios históricos. }\end{array}$ \\
\hline
\end{tabular}

Como puede observarse a partir de este breve resumen de diferentes posturas ante asuntos de gran importancia en la política inglesa del siglo XIX, la visión de los liberales radicales ingleses contiene un componente idealista que la diferencia claramente de otras corrientes dentro del movimiento liberal más orientadas hacia una acción práctica efectiva tanto en la política exterior como en el ámbito de la economía.

Como rasgos definidores del punto de vista de los radicales, podemos apuntar, como indicaba Belloc, a su búsqueda de un ideal de vida civil comprometida con una dimensión moral que enfatiza la libertad y la responsabilidad, y su deseo de que dicho ideal se desenvolviese en paz, tanto a nivel nacional como internacional, como se pone de manifiesto en su visión anti-imperialista y anti-militarista. Responderían de este modo más claramente que otras tendencias a la definición que dio Gregorio Marañón, para quien ser liberal consisten en "primero, estar dispuesto a entenderse con el que piensa de otro modo; y segundo, no admitir jamás que el fin justifica los medios (...). El liberalismo es, pues, una conducta, y, por lo tanto es mucho más 
que una política." 25 En este sentido, se podría afirmar, respecto al enfoque de los liberales radicales, que se trata de un ideal anti-maquiavélico que otorga a los principios y a las consideraciones morales mayor importancia que a las cuestiones prácticas.

Frente a este alma "idealista" de los radicales, que pone la moralidad y el honor por encima de cualquier otra consideración, se desenvolvió dentro del liberalismo inglés otra visión más "utilitarista", centrada en las necesidades prácticas de la política imperial y en el aprovechamiento de las posibilidades de engrandecimiento nacional y enriquecimiento personal que el contexto económico nacional e internacional ofrecía. Esta disyuntiva entre la "Pequeña Inglaterra" 26 de los altos ideales y el poderoso Imperio, con intereses comerciales, políticos y militares por todo el orbe, se mantuvo viva a lo largo del convulso siglo XIX y prevaleció incluso a principios del XX, cuando la realidad política parecía ya definitivamente decantada por las necesidades prácticas del momento.

\section{IV}

\section{RAIICES FILOSÓFICAS DEL LIBERALISMO INGLÉS}

Trataremos a continuación de esbozar sucintamente la naturaleza y el origen intelectual de las diferencias anteriormente señaladas. De acuerdo con Leo Strauss, la tradición clásica y cristiana en filosofía política, que tendía a considerar la acción del gobernante como inspirada por altos ideales y enfatizaba sus obligaciones morales frente a los súbditos, fue rota por el realismo cínico de Maquiavelo, no porque antes de él los gobernantes se hubieran guiado por los principios clásicos y después por los suyos, sino porque fue el primero que se atrevió a consignar esa visión por escrito ${ }^{27}$.

\footnotetext{
25 Marañón (1956).

${ }^{26}$ Los conceptos "Little England" o "Merry England" hacen referencia a una Inglaterra rural e idílica. El prototipo de esta idea es la visión de Cobbett de una Inglaterra de "aldeas y pastos, pequeñas cervecerías y Roast Beef" (Schama, 2005, 131).

27 Strauss, Leo, "Niccolo Machiavelli", en Strauss L. y Copsey J. (eds), History of Political Philosophy, The University of Chicago Press, $3^{\text {rd }}$ edition, Chicago, 1987, p. 296297.
} 
La revolución maquiavélica, que marcó el punto de ruptura entre la filosofía política clásica y la moderna, fue seguida por otros como Bacon o Espinoza, y consolidada por Hobbes. La intención de la obra de Hobbes era doble: por un lado, sentar las bases de una filosofía política y moral de fundamento científico; y por otro contribuir al establecimiento de la paz civil ${ }^{28}$, tan precaria en la Inglaterra de su tiempo.

De este modo, Hobbes trataría de dar forma científica a la ruptura maquiavélica con la tradición que, desde Aristóteles, concebía la filosofía política en referencia siempre a la moral. Pero, al contrario que Maquiavelo, Hobbes trató de elaborar una teoría que, basándose en un concepto de ley natural ajeno a la idea clásica del perfeccionamiento de los seres humanos, fuese útil para el propósito de la convivencia en sociedad ${ }^{29}$. Desde este punto de vista atacó las teorías de Aristóteles, que consideró subversivas y falsas ${ }^{30}$.

El siguiente esquema trata de exponer didácticamente algunas de las diferencias sobre la cuestión entre la filosofía política clásica y cristiana y la moderna. ${ }^{3132}$

TABLA 2: TEORÍAS CLÁSICA Y MODERNA EN FILOSOFÍA POLÍTICA

\begin{tabular}{|c|c|c|}
\hline & Teoría moderna & Teoría clásica y cristiana ${ }^{31}$ \\
\hline Metodología & Científica $^{32}$ & Filosófica y religiosa \\
\hline Base argumental & Abstracción & Historia y Sagradas Escrituras \\
\hline $\begin{array}{l}\text { Fundamento de la acción de } \\
\text { gobierno }\end{array}$ & Práctico & Moral \\
\hline Concepto de comunidad & Mecánico & Orgánico \\
\hline
\end{tabular}

28 Berns $(1987,396)$

29 Ibid, p. 397.

30 Hobbes (1965, cap. XXXI).

31 Tratamos de reflejar el punto de vista de los estudiosos cristianos, desde los apóstoles y la patrística a la escolástica, que tiene sus raíces en los autores grecolatinos (Sócrates, Platón, Aristóteles, Cicerón, ...) cuyas ideas generalmente emplearon y que citaron con profusión. No obstante, estos últimos también resultaron de inspiración para autores modernos. Así, por ejemplo, el escéptico Espinoza se inspiró en las ideas de Tácito (Strauss, 1987, 299).

32 A partir de Hobbes. 
El objetivo declarado de Hobbes es superar la forma tradicional de hacer filosofía política, que pretendía alejar de las universidades en favor de sus propias teorías. Cuando se refiere a crear una nueva teoría política basada en principios científicos, se refiere a la aplicación de dos métodos: el sintético o compositivo, basado en el razonamiento, a partir del cual se deducen posibles causas de efectos observados; y el analítico o resolutivo, que reflexionando sobre los efectos observados trata de deducir sus posibles causas ${ }^{33}$. De este modo, pretende sustituir las concepciones clásicas que, de Aristóteles a Santo Tomás, se tienen de la naturaleza humana, basadas en elementos filosóficos y religiosos, y sustituirlas por su propia teoría sobre el "estado de la naturaleza". Ese estado natural, razonado a partir de las experiencias negativas de su época, es de violencia pues existe, deduce Hobbes, "una proclividad natural de los hombres a hacerse daño los unos a los otros"34.

La ruptura metodológica respecto al análisis histórico, que es sustituido por Hobbes y otros autores por la abstracción de un "estado de la naturaleza", de cuyas características habrá de depender la visión del autor sobre las formas de gobiernos y el sentido y uso de la autoridad, lleva al "contractualismo social", una herramienta necesaria para deducir el paso de ese estado natural teórico, en el que aún no existe una autoridad pública, a las sociedades y gobiernos constituidos. Para Dalmacio Negro Pavón, el contractualismo lleva a sustituir dos concepciones naturales como pueblo y gobierno por dos artificios, provenientes de un estado imaginado de las cosas sobre el cual trabaja la abstracción para dar lugar a la teoría política, que son la sociedad y el estado ${ }^{35}$.

33 Berns (1987, 397).

34 Godwin $(1987,485)$

35 "El contractualismo descansa en la imaginaria preexistencia de un estado de la naturaleza. En semejante estado, una situación política extremada, no hay un pueblo sino sólo un conjunto de individuos dispersos que, sumidos en un miedo permanente a perder todo lo suyo, en primer lugar la vida, apenas coexisten. Para hacer de él un lugar de convivencia inventó Hobbes sus dos grandes artificios. La Sociedad como el lugar en el que el conjunto de los individuos busca la satisfacción de su egoísmo. El Estado para garantizar la vida social - la justicia -, con su poder de coacción. Es como si en la Sociedad se coexistiera y en el Estado se conviviera." (Negro Pavón, 2008, 14). 
Frente a la visión negativa de Hobbes sobre el ser humano, que tiende a justificar estilos de gobiernos autoritarios, John Locke parte de un estado de la naturaleza menos violento, y plantea menos atención la cuestión de la autoridad pública como solución a los problemas de la convivencia y más al tema de la propiedad.

La teoría política de Locke, expuesta con amplitud en su obra “Dos tratados sobre el gobierno" (1690), tomó como punto de partida la crítica a la doctrina de la justificación divina del poder absoluto del rey que realizara Robert Filmer ${ }^{36}$, reflejada en su obra $E l$ patriarca (publicada a título póstumo en 1680). En ella, Filmer critica la idea del consentimiento y emplea un símil entre la figura del monarca y un padre de familia, que tiene plena potestad sobre sus hijos del mismo modo que el primero la tendría sobre sus súbditos. Resulta significativo que Filmer considerase que el principal enemigo ideológico de la tesis del derecho absoluto de los reyes era el pensamiento escolástico ${ }^{37}$.

\section{$\mathrm{V}$ \\ LA FILOSOFÍA POLÍTICA DE SUÁREZ}

La filosofía política de Francisco Suárez presenta dos rasgos de singular interés para nuestro estudio: está enraizada en la tradición clásica y cristiana, y, al mismo tiempo, presenta matices modernos de tinte "democrático", que se derivan de la idea fundamental de la necesidad de consentimiento por parte de los súbditos. No es extraño que Suárez, junto con el también jesuita cardenal San Roberto Belarmino, fuera el blanco de las críticas de Filmer a estas nuevas ideas en El patriarca. En el primer libro de su obra, Filmer polemiza fundamentalmente con Belarmino en contra de la supremacía del Papa sobre el Rey, y en el segundo, titulado "Es antinatural que el pueblo gobierne o elija gobernantes", sobre todo con Suárez ${ }^{38}$.

\footnotetext{
36 Godwin $(1987,476)$

37 Migliore $(2009,191)$

38 Ibid, pp. 192-193.
} 
Filmer consideraba a Belarmino y a Suárez como los principales propagandistas de las ideas propias de las teorías contractuales del origen del poder político, que reconocían incluso la legitimidad, bajo ciertas circunstancias ${ }^{39}$, de una rebelión popular contra el poder civil. Además, la apreciación acerca del cumplimiento de dichos requisitos correspondería, se entiende que sobre una base moral, a la propia población, conclusión que Filmer caracterizó como "pestilente y peligrosa" ${ }^{40}$. En opinión de Filmer, el apoyo de los jesuitas a estas teorías que consideraba subversivas tenía la finalidad de socavar la autoridad del poder civil y enfatizar la del Papa $^{41}$.

La principal obra de Suárez en relación a sus ideas sobre filosofía política es el Tractatus de legibus ac Deo legislatore, escrito en $1612^{42}$. En el tratado de las leyes se asientan las bases de su filosofía política. Esta filosofía, de acuerdo con la caracterización que propusimos (véase Tabla 6.2) tendría los elementos propios de la tradición clásica y cristiana, a la que Suárez refiere constantemente en su tratado.

La argumentación de Suárez parte de una rica exposición del pensamiento de autores precedentes (desde los filósofos griegos y romanos hasta los escolásticos de su época, pasando por la patrística y por Santo Tomás). Así, la erudición del Doctor Eximio hace que su obra resulte muy apreciable también como compilación de ideas anteriores en torno a un asunto determinado.

Su visión respecto a los asuntos políticos da prioridad a las cuestiones morales. Así, al igual que Aristóteles, considera que el vínculo que une a los ciudadanos entre sí es de naturaleza moral ${ }^{43}$. Pone explícitamente de manifiesto lo que considera el error de

39 Para Suárez habría dos casos en los que estaría justificada una rebelión contra el gobernante: que un tirano llegase al poder careciendo de justo título (tyrannus in titulo); o que el gobernante, aun teniendo justo título, haga un mal uso del poder que dañe el bien común (tyrannus in regimene). (Ward, 2004, 41).

40 Filmer $(1680,10)$.

41 Ward $(2004,41)$.

42 Otras obras importantes de filosofía política y del derecho son: Defensio fidei catholicae et apostolicae adversus Anglicanae sectae errores (1613), y De opere sex dierum (que deja inacabada a su muerte en 1617).

43 Suárez (1918), Vol. I, 122, De Legibus, Libro I, cap. 6, 12. 
Maquiavelo, seguido por los políticos de su tiempo, que atendiendo a la primacía de las cuestiones prácticas ${ }^{44}$ se atiene a su "juicio perverso" consistente en que "no puede ser rey verdadero y estable el que se ciñe a las leyes de la virtud y se somete totalmente a ellas" 45 .

$\mathrm{Al}$ contrario que los modernos contractualistas, Suárez no parte de un "estado de la naturaleza" abstracto en el que se da un conglomerado de hombres que, en términos de Dalmacio Negro, tan sólo "coexisten" pero no "conviven"46. Para Suárez, la comunidad entendida "solo como un conglomerado sin orden alguno ni unión física o moral" no forma un cuerpo político "y por eso mismo no necesitan de una cabeza o príncipe" ${ }^{\prime \prime 7}$. Es preciso, indica Suárez, considerar a la multitud humana bajo otro prisma, según el cual "por especial voluntad o común consentimiento se reúnen en un solo cuerpo político por un vínculo de sociedad y para ayudarse mutuamente en orden a un fin político, del cual modo forman un solo cuerpo místico, el cual puede llamarse de suyo uno; y, por consiguiente, necesita él de una sola cabeza." 48

Frente al mecanicismo de otros autores que emplean el símil del contrato, la visión suareciana de la comunidad humana es claramente orgánica y natural. Y es que para Suárez la comunidad política no es un mero pacto de intercambio de libertad por seguridad, como podría deducirse de las tesis de Hobbes. Para Suárez, si bien la formación de la comunidad se produce por voluntad o consentimiento, el poder de la misma no dimana de ese consentimiento, pues "esta potestad no está en cada uno de ellos ni total ni parcialmente; ni siquiera existe en la misma ruda (por así decirlo) colección o agregado de hombres." ${ }^{\prime 4}$ Ese poder, que no aparece en la naturaleza humana "hasta que los hombres se reúnen en una

${ }^{44}$ Fundándose únicamente en que "no puede de otro modo conservarse la república temporal" (Suárez, 1918, Vol. III, p. 142. De Legibus, Libro III, cap. 12, 2).

${ }^{45}$ Suárez (1918), Vol. III, p. 142. De Legibus, Libro III, cap. 12, 2.

46 "La explicación de la existencia de las sociedades por un acto de voluntad cae en la interpretación utilitarista, que, absolutizada como la de Hobbes y los contractualistas en general, es completamente falsa y retrotrae la convivencia a la mera coexistencia" (Negro Pavón, 2008, 19).

47 Suárez (1918), Vol. III, p.23. De Legibus, Libro III, cap. 2, 4.

48 Ibid.

${ }^{49}$ Ibid, p.26-27, De Legibus, Libro III, cap. 3, 1. 
comunidad perfecta y se unen políticamente" 50 , tendría para Suárez un origen divino y se daría como una propiedad que se sigue por la propia naturaleza de la comunidad como cosa.

En este sentido, aclara Suárez, "la voluntad de los hombres solo es necesaria para componer una comunidad perfecta; mas, para que tal comunidad tenga la predicha potestad, no es necesaria especial voluntad de los hombres, sino que se sigue por la naturaleza de la cosa y por la providencia del autor de la naturaleza"51. De acuerdo a esto, se podrían entender las normas naturales que regulan la comunidad política, como la existencia de un cierto poder sobre sus miembros, como un fenómeno propio del ser humano pero en el que la voluntad humana juega un papel limitado, del mismo modo que, no en el ámbito político sino en el económico, Luis de Molina identificó en su tratado De iustitia et iure (1593) sucesos de esta naturaleza que "son el resultado de la acción humana, pero no del designio humano" 52 .

Podría decirse, de acuerdo con las características de una y otra que antes hemos señalado, que Suárez toma los elementos esenciales de la tradición clásica y escolástica, pero introduce elementos propios de la filosofía política moderna, como la idea del consentimiento y su visión peculiar del símil contractual o del pacto de voluntades constitutivo de la comunidad política. Sin embargo, parece que su visión orgánica de la comunidad, espacio de convivencia natural con sus propias leyes a menudo independientes de la voluntad humana, contrasta vivamente con la visión de los contractualistas sociales de una sociedad artificial, fruto de un acuerdo utilitarista entre sus miembros.

\section{$\mathrm{VI}$}

\section{SUÁREZ EN INGLATERRA}

Pese a que Locke partió de la crítica a las teorías de Filmer, no incluyó ninguna referencia en sus obras a los antagonistas

\footnotetext{
50 Ibid, p. 29-30, De Legibus, Libro III, cap. 3, 5.

${ }^{51}$ Ibid, p. 31.

52 Gómez Rivas $(2014,25)$.
} 
intelectuales de éste en la cuestión del derecho absoluto de los reyes. Filmer había citado en El Patriarca las tesis de Belarmino y Suárez $^{53}$, a los que podemos entender que consideraba como las figuras más relevantes del pensamiento europeo de su época que defendían ideas opuestas a su absolutismo monárquico de justificación divina. Poniendo sus teorías curiosamente junto a las de Calvino, criticaba en particular la idea de la libertad natural de los súbditos y la posibilidad de otras formas de gobierno legítimas distintas de la monarquía ${ }^{54}$.

Locke, sin embargo, no citó en ninguna de sus obras a Suárez, y tan solo en una ocasión a Belarmino. Locke solo en una obra de su juventud Essays on the Law of Nature (escrita en 1663 pero no publicada hasta 1954) llega a citar a Santo Tomás ${ }^{55}$. También citó, fuera del contexto de la filosofía política, la Historia de España de Juan de Mariana en su obra History of Navigation from its Origins to this Time $(1704)^{56}$. Es improbable que la razón de la ausencia de estas citas en el ámbito de la teoría política fuese el desconocimiento de dos autores que habían sido el blanco de las críticas de Filmer en $E l$ Patriarca porque representaban una línea de pensamiento opuesta al poder absoluto de los monarcas. Más plausible parece suponer que la razón no fuera otra que la necesaria prudencia, en el turbulento ambiente político y religioso de la Inglaterra de su tiempo, a la hora de citar y fundamentar argumentos sobre teoría políticas sobre fuentes católicas y particularmente jesuitas.

A partir del cisma, tiene lugar un progresivo enrarecimiento clima intelectual inglés, caracterizado por la coexistencia de fuerzas que intentan superar lo medieval con otras que pretenden recuperarlo en parte. Se produce un cierto desdén hacia el pensamiento de los doctores de la Iglesia, sobre todo contra Santo Tomás, y un fuerte celo sobre todo lo que pueda implicar apoyo a la autoridad de Roma. La animadversión hacia lo católico se extendía a Aristóteles. Desde principios del siglo XVII, cuando la resistencia

53 En El Patriarca Suárez es mencionado trece veces y Belarmino veinte, en tanto que Scoto es mencionado en una sola ocasión y Calvino en dos.

54 Migliore $(2009,193)$

55 Ibid, p. 196.

56 Fernández Álvarez $(2017,218)$ 
dentro de la población inglesa al cisma con Roma fue vencida casi completamente, y en muchos aspectos hasta tiempos no muy lejanos (la emancipación legal de los católicos en Inglaterra no se llevó a cabo hasta 1829 , pero los prejuicios continuaron hasta mucho después), el catolicismo y particularmente la Compañía de Jesús estuvieron muy denostados y las sospechas de poseer o leer obras de estos autores podría traer consigo el oprobio social, además de tener graves consecuencias legales ${ }^{57}$.

La polémica obra Defensio Fidei, escrita a instancias del Papa Pablo V en relación a la actitud que los católicos ingleses habían de adoptar ante el Juramento de Lealtad ${ }^{58}$ que en 1606 Jacobo I decidió exigir a sus súbditos, no fue la única de Suárez que tuvo difusión Inglaterra. Su monumental Tractatus de legibus ac Deo legislatore, escrito en 1612, un año antes que Defensio Fidei, fue reimpreso en Londres en 1679, bajo el reinado de Carlos II, cuyo intento ${ }^{59}$ de restaurar las libertades religiosas permitió de nuevo la publicación y lectura de las obras de los jesuitas. Pese a que Defensio Fidei resultó una obra muy conocida en su época por la polémica intelectual con Jacobo I y sus repercusiones políticas, la obra de Suárez más citada entre los autores ingleses en filosofía política fue su tratado De legibus.

57 De acuerdo con la crónica de J. de la Servière, a la raíz de la polémica sobre Defensio Fidei en 1613 "el libro de Suárez fue quemado en Londres y su lectura prohibida en Inglaterra bajo las penas más graves" (Migliore, 2009, 191).

58 Tras el denominado "motín de la pólvora" (1605) se inició una ola de persecución a los católicos en Inglaterra. Para asegurar la lealtad de sus súbditos y desenmascarar a aquellos que seguían siendo fieles al Papa, Jacobo I exigió a sus súbditos en 1906 un juramento de lealtad, en el que se debía reconocer expresamente que "ni el Papa ni ninguna autoridad en Roma tiene poder alguno para deponer al Rey". El Papa Pablo V se opuso expresamente a la exigencia de este juramento, encargando exponer sus argumentos en un opúsculo al cardenal Belarmino. El opúsculo recibió una réplica por escrito a instancias de Jacobo I, que se encargó de que la réplica tuviera amplia difusión por las cortes europeas. Tras la sucesión de réplicas y contrarréplicas, el Nuncio Apostólico de Su Santidad en España, monseñor Caraffa, solicitó a Francisco Suárez la composición de una obra, Defensio Fidei, que zanjara definitivamente la cuestión (López Atanes, Bustos, y Villena, 2010, 113).

59 Nunca completado por la oposición del Parlamento, que le obligó a retirar en 1672 la Royal Declaration of Indulgence, que otorgaba libertad de culto a católicos y disidentes protestantes. La emancipación de los católicos no sería promulgada hasta 1829. 
Si Locke no citó a Belarmino y a Suárez, Algernon Sidney, contemporáneo de Locke y también reivindicador de la libertad natural del hombre y de la necesidad de consentimiento respecto del gobierno civil, lo hizo con profusión. Para Sidney la sujeción al poder sería el producto de acuerdos contractuales entre seres humanos que son naturalmente libres, aunque hayan podido nacer ya sujetos a leyes ${ }^{60}$. Sidney, en sus Discursos sobre el gobierno, criticó, al igual que Locke, las teorías absolutistas de Filmer, pero temió la coincidencia con los jesuitas más que Locke, si fuera ésta la causa de la falta de referencias a los mismos en sus obras, como puede deducirse del tono de las citas a éstos.

Sidney justifica su peligrosa coincidencia de punto de vista con los jesuitas diciendo que "las nociones comunes no son de la escolástica, sino de la naturaleza" y enfatiza que semejantes ideas, que constituyen en su opinión "buena teología", también han sido defendidas por las iglesias reformadas ${ }^{61}$. Su escaso aprecio por el catolicismo y por los jesuitas en particular, que habían llevado el peso de la Contrarreforma tanto en Inglaterra como en el resto de Europa, se aprecia en expresiones críticas con quienes según él "se consagran a la sofistería escolástica como la mejor manera de defender la idolatría" o referencias directas como "No me preocupa hacer bueno a Suárez. Un jesuita puede decir la verdad; pero debería ser recibida, como del demonio, con precaución"62.

VII

WILLIAM COBBETT

Siglo y medio después de que Sidney hubiera lamentado coincidir con los escolásticos tardíos españoles en la cuestión del consentimiento, si bien las medidas más crueles habían sido eliminadas, los católicos ingleses seguían teniendo sus derechos gravemente restringidos. Se podría decir que la vida social y política de un católico ilustre, como el poeta Alexander Pope, en el siglo XVIII, fue

\footnotetext{
60 Ward $(2004,161)$

${ }^{61}$ Migliore $(2009,197)$

62 Citas de "Discursos sobre el gobierno" de Sidney en Migliore (2009, 198-199).
} 
mucho más difícil que la de los músicos cortesanos William Byrd y John Dowland a finales del XVI y principios del XVII. Aunque a principios del siglo XIX los castigos más crueles habían sido derogados y las leyes más restrictivas no solían observarse en la práctica, los católicos ingleses todavía tenían prohibido ser poseer tierras, ser parlamentarios o ejercer ciertas profesiones, y seguía siendo un delito la asistencia a la Eucaristía o la construcción de una Iglesia Católica ${ }^{63}$.

La ley de emancipación de los católicos no llegaría hasta 1829. Uno de sus principales impulsores fue el periodista, granjero y político radical William Cobbett, que, siendo anglicano, fue uno de los primeros ingleses en dejar por escrito una visión crítica sobre las consecuencias económicas y sociales de la Reforma Protestante en su país. Cobbett, que comenzó su carrera como periodista al servicio del gobierno de $\mathrm{Pitt}^{64}$, acabó siendo un radical defensor de las libertades individuales y del libre comercio, y contrario a los privilegios de los terratenientes. Debido a este cambio en la orientación de su acción política y social, suele decirse sufrió un proceso de conversión del conservadurismo al radicalismo, si bien G.K. Chesterton escribió lo contrario en su biografía de Cobbett ${ }^{65}$. En cualquier caso, el perfil de Cobbett no era el típico de los liberales radicales de su tiempo. Visitó Francia en plena Revolución y, en varias ocasiones, la recientemente emancipada Norteamérica, y no

63 Cobbett $(2009,1)$.

64 Regresó a Inglaterra en 1800, tras haber pasado un año en Francia y siete en Estados Unidos tratando de evitar la prisión por haber escrito un panfleto de queja sobre las condiciones de vida en el ejército. No sería último de sus escritos que la traería problemas como el exilio o la cárcel. En Estados Unidos llevo a cabo la difícil tarea de escribir artículos desde un punto de vista pro-británico, empleando por su propia seguridad el irónico seudónimo de Peter Porcupine (puercoespín). Tras su regreso a Gran Bretaña, Pitt y William Windham subvencionaron un periódico patriótico de tirada diaria al que Cobbett denominó, en honor de sus años en América, The Porcupine. (Schama, 2005, 116).

65 "It is not true that he belonged successively to two parties: it is much truer to say that he never belonged to any. But in so far as there were elements of the Radical in him at the end, there had been traces of them from the beginning. And in so far as he was in one sense a Tory at the beginning, he remained a Tory to the end." (Chesterton, 1910, 22) 
ocultó su antipatía por ambos procesos ${ }^{66}$. Su patriotismo inglés le mantuvo alejado del espíritu internacionalista de otros radicales.

De haberse producido un cambio radical en su pensamiento, como defienden la mayoría de sus biógrafos, su camino de Damasco habrían sido sus visitas al campo, alrededor de los años 1803-1804, en las que se interesó vivamente por la condiciones de vida del campesinado inglés. Observó que las pocas aldeas que aún conservaban terrenos comunitarios que no habían sido convertidos en enclosures eran, pese a las teorías de Arthur Young ${ }^{67}$, las más prósperas y que los mayores índices de pobreza y miseria no se encontraban, como solía pensarse, en el norte de Inglaterra, que mostró mucha más resistencia antes los cambios religiosos y económicos de los siglos anteriores, sino en el área del sureste que iba desde el "cinturón de grano" alrededor de Londres hasta East Anglia, donde las explotaciones era de mayor tamaño y su actividad se orientaba con más claridad hacia la maximización de beneficios ${ }^{68}$.

Cobbett, que recorrió Inglaterra estudiando las condiciones de vida de los campesinos y defendiendo en numerosos pleitos sus intereses frente a los grandes propietarios, llegó a la conclusión de que el lamentable estado de la vida rural en su país fue consecuencia directa de las reformas religiosas llevadas a cabo en su país desde el reinado de Enrique VIII, que habían puesto, en sucesivas etapas, casi toda la tierra en manos de un pequeño grupo de familias cercanas al poder, como defendió en su obra "Historia de la Reforma", publicada en 1824. Para él la reforma fue "engendrada en lujuria", "llevada a cabo con hipocresía y perfidia", "devastó y expolió el país", "produjo gran pobreza y miseria" y en ella, escribe con su habitual vehemencia, "se sientan las bases del pauperismo, esa desgracia inmoral, esa terrible prevalencia de crímenes de todo tipo que tan fuertemente marca ahora el carácter de esta nación, que fue en el pasado una tierra de virtud y prosperidad. ${ }^{69}$

66 Chesterton $(1910,21)$

67 Arthur Young (1741-1820) escribió sobre agricultura y economía agraria en contra de los terrenos comunitarios que, en su opinión, suponían una pérdida económica en relación con las grandes explotaciones cercadas y en manos de un solo propietario. 68 Schama $(2005,117-118)$

69 "We have seen, then, that the "Reformation" was engendered in beastly lust, brought forth in hypocrisy and perfidy, and we have had some specimens of the acts 
Frente a las tradicionales acusaciones de intentos de injerencia política desde Roma cada vez que el Papa se pronunciaba sobre los asuntos de Inglaterra, Cobbett defendió que "el Papa no tenía más poder que el que se derivaba de la libre voluntad de la gente. El pueblo estuvo con frecuencia a su lado, en sus enfrentamientos con los reyes; $y$, por este medio, en numerosas ocasiones preservó sus derechos contra los intentos de los tiranos." ${ }^{70}$ Cobbett no solamente creía que la acción política debía regirse por la moral, sino que veía ventajas en la existencia de una autoridad moral externa que, de alguna manera, "fiscalizase" desde ese punto de vista las actuaciones del poder civil.

La visión liberal de Cobbett se aleja de la filosofía política de Hobbes ${ }^{71}$ y se muestra más acorde con la de Locke ${ }^{72}$. Sin embargo,

by which it caused innocent blood to be shed. We shall now, in this Letter and the next, see how it devastated and plundered the country, what poverty and misery it produced, and how it laid the sure foundation for that pauperism, that disgraceful immorality, that fearful prevalence of crimes of all sorts, which now so strongly mark the character of this nation, which was formerly the land of virtue and of plenty." (Cobbett, 2009, 38).

70 “(...) the POPE had no power but that which he derived from the free will of the people. The people were frequently on his side, in his contests with Kings; and, by this means, they, in numerous instances, preserved their rights against the attempts of tyrants." (Cobbett, 2009, 31-32).

${ }^{71}$ Si bien Malcolm encontró un paralelismo entre ambos en el sesgo conspiratorio del Leviatán de Hobbes y lo que Cobbett denominó "la cosa", un sistema opresivo que extendía sus tentáculos sobre todas las cosas (Collins, 2015, 95-120).

72 No tanto con Algernon Sidney, a quien se refiere del siguiente modo, en relación a su condena y ejecución por haber por alta traición: "If any man ever deserved an ignominious death, this SIDNEY deserved his. He did not deny, he could not deny, that the conspiracy had existed, and that he was one of its chiefs. He had no complaint but one, and that related to the evidence against him. There was only one parole witness, to his acts, and, in cases of high treason, the law of England required two." (Cobbett, 2009, 156-157). Sidney, a instancias de Zuylestein, el enviado de Guillermo de Orange, redactó de su puño y letra y firmó junto con otros seis la carta de invitación a éste para entrar en Inglaterra al frente de un ejército en junio de 1688 , acontecimiento que terminó produciéndose cinco meses más tarde y que fue conocido como "Revolución Gloriosa". Los firmantes pretendía poner fin al reinado de Jacobo II, último rey católico de Inglaterra, y evitar la futura coronación de su recién nacido heredero que a buen seguro profesaría la misma fe, pues su madre era también católica. Otra de las señales que alarmó a los opositores a Jacobo fue su política favorable a la libertad religiosa de católicos y protestantes disidentes, concretada en la publicación de la Declaración de Indulgencia de 1687, que fue posteriormente rechazada por el Parlamento (Belloc, 2005, 437-441). 
en consonancia con su antipatía por las revoluciones americana y francesa, Cobbett lamentaba que las teorías sobre el gobierno de Locke pudieran haber servido de base para los "sistemas destructivos" de Paine y Priestley, así como para otras visiones modernas fundamentadas en el escepticismo, cuando no directamente en la negación "de la propia existencia de Dios"73.

Sus opiniones sobre el proceso revolucionario en Francia, de cuyos primeros años fue testigo directo, coinciden más con las de Burke que con las de Fox o Priestley. Sobre éste último escribió que "la experiencia de una Utopía que nunca ha existido fuera de una mente delirante". Sobre Paine opinaba, al igual que Burke, que sus declaraciones de benevolencia y su humanidad eran "como todas las de los filósofos reformadores de los ilustrados tiempos presentes, del tipo especulativo"74.

\section{VIII}

\section{COBBETT Y SUÁREZ}

Si bien es cierto que existen pocas influencias más improbables para un anglicano de finales del siglo XVIII y principios del XIX que la de un jesuita español que cuestionó directamente la autoridad del Rey de Inglaterra y cuyos libros fueron quemados públicamente y prohibidos, podríamos afirmar que las teorías de Suárez en materia de filosofía política resultaban más concordantes con la mentalidad de Cobbett que las que hemos venido calificando como "modernas". Cobbett, partidario radical de la libertad

73 "It has been unfortunate for the world, that so great and upright a man as Mr. Locke (led astray by the circumstances of the times in which he lived, and the zeal of controversy) should have been the patron and advocate of this baneful, but, in his hands, too plausible and specious doctrine. Locke's fate has indeed been singular. He was a good subject and a pious Christian. Yet, as his theory of government has served for a basis to the destructive systems of the Condorcets, Priestleys, and Paines, so his metaphysical principles have become the ground-work of the vain wisdom and false philosophy which began by denying the existence of the material world, and proceeded, in the writings of the late Mr. Hume and others, to extend that wild scepticism of an ingenious and well-intentioned prelate (bishop Berkeley) to the disbelief of spirit also, of the immortal nature of man, and the being of God himself." (Cobbett, 1819b, 831).

74 Grande $(2016,48)$ 
individual y contrario a los abusos de los poderosos que mantenía al mismo tiempo una visión más bien tradicionalista de las cuestiones sociales y nacionales, se mostró favorable a la posición del Papado en su revisión histórica del cisma que dio origen a la Iglesia de Inglaterra. Concretamente, se mostró partidario del Papado como autoridad moral capaz de prevenir los abusos del poder civil, aludiendo a la figura de Montesquieu ${ }^{75}$, famosamente partidario de un sistema de contrapoderes. La visión de Cobbett sobre la historia de su país desde tres siglos atrás ponía el énfasis en las desastrosas consecuencias de la ruptura del precario equilibrio entre la auctoritas de la Iglesia y la potestas del poder civil. Aunque fueron los monarcas ingleses los que se enfrentaron directamente con Roma en multitud de pleitos, Cobbett enfatiza el papel de una minoría de terratenientes interesados en socavar tanto el poder de la corona como la influencia del Papado ${ }^{76}$.

William Cobbett llevó a cabo una amplia recopilación de archivos parlamentarios, desde la conquista normanda hasta 1803, que editó bajo el título Parliamentary History of England. En esta obra se refleja de manera singular el clima anticatólico de la política inglesa desde tiempos de Enrique VIII, pero también sirve para testimoniar la difusión de la obra de Francisco Suárez entre las élites intelectuales inglesas. Así, en el proceso de recusación parlamentaria ${ }^{77}$ contra Roger Manwaring ${ }^{78}$ en 1628.

75 "MONTESQUIEU observes, that the people of Spain and Portugal would have been absolute slaves, without the power of the Church, which is, in such a case, the only check to arbitrary sway."' (Cobbett, 2009, 31).

76 "If the POPE had had no power, there must have sprung up an Oligarchy, or a something else, to check the power of the King: or, every king might have been a Nero, if he would. We shall soon see a worse than Nero in Henry VIII.; we shall soon see him laying all law prostrate at his feet; and plundering his people, down even to the patrimony of the poor." (Cobbett, 2009, 32).

77 En inglés impeachment.

78 Roger Manwaring (o Mainwaring o Maynwaring) (1590-1653) fue un clérigo anglicano y capellán real de Carlos I de Inglaterra. Sus sermones en favor de éste, tendentes a justificar la legitimidad del rey para establecer impuestos incluso con la oposición del parlamento, le costaron un proceso de recusación parlamentaria tras el cual fue suspendido de sus funciones, encarcelado y multado. Se trató de un típico episodio en la larga y tensa disputa entre Carlos I y el Parlamento inglés que desembocó en la Guerra Civil (1642-1651). Manwaring es citado por Sidney junto a Filmer y Hobbes 
Manwaring había empleado argumentos de Suárez sobre la legitimidad de los impuestos en sus sermones en defensa de la posición de Carlos I. En el proceso del parlamento contra él, iniciado por razón del signo absolutista de su predicación, Robert Mason ${ }^{79}$ afirmó que semejantes citas resultaban inapropiadas. De nuevo empleó la típica cautela al citar la obra de Suárez, diciendo "espero que sea tan lícito para mí citar a un jesuita, como lo es para el doctor Manwaring falsificarlo" ${ }^{80}$. Concretamente lo hace al capítulo XVII, en el que Suárez trata el tema del papel del consentimiento de los súbditos en las leyes tributarias. Manwaring argumentaba que para Suárez no era preciso el consentimiento del pueblo para los tributos. Mason le corrigió diciendo que también dice Suárez que los Reyes de España están atados a solicitar consentimiento por razón de la tradición y la ley, pues así lo concedieron sus antecesores desde dos siglos atrás ${ }^{81}$.

John Pym ${ }^{82}$, insiste en la línea de acusación de Mason al citar con mayor amplitud el capítulo XVII de De legibus ${ }^{83}$. Pym argumenta que el beneficio concedido por los Reyes de España (no imponer tributo sin consentimiento) no fue sino por el propio interés del reino y que "el éxito y la prosperidad de ese reino, a través del valor y la industria de la nación española, avanzó gracias a esa

en la lista de autores frente a los que no se avergonzaba de coincidir con Suárez y Belarmino en estar en contra (Migliore, 2009, 198).

${ }^{79}$ Robert Mason (1579-1635), miembro del parlamento por Winchester.

80 "I hope it is as lawful for me to cite a Jesuit, as it is for Dr. Manwaring to falsify him; Suarez, in his first book, de Legibus, c. 17. delivereth his opinion in these words, Amplitudo \& restrictio potestatis rogum, circa ea qua per se mala velinjusta non sunt, pendent ex arbitrio hominum, \& ex ambigua conventione, vel pacto, inter reges \& regnum.'” (Cobbett, 1819b, 360).

${ }^{81}$ Cobbett $(1819 b, 360)$.

82 John Pym (1584-1643), prominente parlamentario inglés del sector crítico con el Rey, fue uno de los cinco miembros del parlamento a los que Carlos I mandó arrestar, si éxito, en 1642, suceso que es considerado el detonante de la Guerra Civil Inglesa.

83 "It was secondly observed, that (in the p. 27 of his first sermon) he cites these words, 'Suarez de Legibus, lib. v. c. 17. Acceptationem populi non esse conditionem necessarian, ex vi juris naturalis aut gentium, neque ex jure communi.' The Jesuit adds, 'neque ex antiquo jure Hispania: ;' which words are left out by the doctor, lest the reader might be invited to enquire what was 'antiquum jus Hispania:"' (Cobbett, $1819 b, 398)$. 
sabia decisión"84. Pym relaciona también las tesis suarecianas en torno a los tipos de tributos y su importancia relativa de cara a la legitimidad del gobierno para su exigencia al pueblo ${ }^{85}$, y hace gala de los típicos prejuicios anticatólicos al decir que Manwaring, "peor que un jesuita" 86 , extiende la prerrogativa real de exigir impuestos sin consentimiento a todas las figuras tributarias.

Finalmente, Manwaring tuvo que pedir perdón por haber citado a un jesuita como Suárez en sus sermones ${ }^{87}$, circunstancia que tuvo un peso significativo en las acusaciones del sector puritano y anticatólico contra él.

Es destacable que la polémica se centrase a torno a la obra $D e$ Legibus, demostrando que no solo Defensio Fidei, más relativa al ámbito particular inglés, era de amplio conocimiento entre los eruditos de aquel país.

Medio siglo después de la caída en desgracia de Manwaring, una vez pasada la Guerra Civil y la dictadura de Cromwell y habiendo sido restaurada la monarquía en la persona de Carlos II, las tensiones entre el parlamento y la corona estaban lejos de haber cesado. Entre 1678 y 1681 se desató el denominado "motín papista" 88 , un supuesto complot que sirvió, como en otras ocasiones en la historia de Inglaterra, para incrementar la represión sobre lo

\footnotetext{
${ }^{84}$ Cobbett $(1819 b, 398)$

85 "The doctor cites (p. 20 of his first sermon) these words out of the same Suarez, de Legibus, Lib. v. cap. 15. fol. 300. 'Tributa esse maxime naturalia, \& praese ferre justitiam, quia exiguntur de rebus propriis;' this he productii in proof of the just right of kings to lay tributes. And no man, that reads it, doubts, but that, in the opinion of Suarez, the king's interest and property in the goods of his subjects is the ground of that justice; but the truth is, that Suarez,in that chapter, had distributed tributes into divers kinds (...)" (Cobbett, 1819b, 398).

86 Cobbett $(1819 b, 399)$.

87 "Dr. Manwaring made a short reply touching his said two assertions: and said, That he denied not justice and law to be between king and people; but affirmed that the king's justice could not be requited: and excused himself for citing of Suarez, for in those places he spake for the king."' (Cobbett, 1819b, 414).

88 "Papish plot", un supuesto complot de católicos ingleses para atentar contra la vida de Carlos II. La existencia de un complot fue denunciada en un manuscrito por Titus Oates, principal acusador, y el clérigo anglicano Israel Tonge. El supuesto complot desató una oleada de histeria anti-católica. Posteriormente se demostró que Oates mentía, seguramente resentido porque le fue negada la entrada en la orden de los jesuitas, y fue condenado por perjurio.
} 
católicos ingleses y aprobar la "ley de exclusión", posteriormente derogada ${ }^{89}$, para prevenir el acceso de Jacobo, hermano de Carlos, al trono.

Cobbett recoge en el volumen VII de su recopilación Complete collection of State Trials algunos de los juicios a los que dio lugar el supuesto complot católico para asesinar a Carlos II. En el juicio a Richard Langhorne ${ }^{90}$ se incluye un panfleto anónimo ${ }^{91}$, probablemente obra de un clérigo de la Iglesia Anglicana, que fue publicado en 1679 con la finalidad de rebatir las últimas palabras de los cinco jesuitas ejecutados el 20 de junio de ese mismo año en Tyburn ${ }^{92}$. En dicho panfleto se argumenta que los jesuitas en general, y no solo Juan de Mariana, están a favor de la doctrina del "asesinato de reyes" 93 y se mencionan las palabras de Suárez "un jesuita de tal reputación que su juicio se valora más que el de otros mil autores"94, afirmando que cuando un rey es depuesto (con la autorización del Papa) y sigue en el cargo se convierte en un tirano o usurpador, pudiendo, según interpreta el autor del panfleto, ser asesinado a consecuencia de ello ${ }^{95}$. El panfleto incluye referencias

${ }^{89}$ La prohibición de acceso de un católico al trono de Inglaterra volvió a estar en vigor a partir de 1707, con la creación del Reino Unido, y continúa aún vigente.

90 Richard Langhorne (1624-1679), abogado inglés, sospechoso durante el "motín papista" por ser católico y asesorar legalmente a los jesuitas, fue procesado por alta traición y ejecutado en Tyburn en 1647. Fue beatificado en 1929 por Pío XI.

91 "Animadversions on the last Speeches of the five Jesuits, viz. Thomas White alias Whitebread, Provincial of the Jesuits in England; William Harcourt, Pretended Rector of London; John Fen wick, Procurator for the Jesuits in England; John Gavan alias Gawen, and Anthony Turner; who were all executed at Tyburn for High Treason in conspiring the Death of the King, \&c. June 20, 1679". (Cobbett, 1819).

92 Thomas Whitbread, William Harcourt, John Fenwick, John Gavan y Anthony Turner, todos ellos beatificados por Pío XI en 1929.

93 Cobbett $(1819,546)$

94 Ibid, p. 547.

95 Referencia a Defensio Fidei (libro VI, cap.4, números 14 a 17): “When a king is deposed, then he is neither lawful king nor prince ; and if therefore he endeavour to keep the kingdom under him by strength, then he is an usurper, no lawful king, having no true title to the crown ; for that (h) after the decree of deposition, he is altogether deprived of his kingdom, so that he caniiot with a just title possess, and so may be used as a tyrant or usurper, and by consequence may be slain by any private man." (Cobbett, W., Complete collection of State Trials, Vol. VII, T. C. Hansard, Londres, 1819, p. 547). Sin embargo, el autor del panfleto no tiene en cuenta que en el número 19 del mismo capítulo Suárez limita la legitimidad de una acción violenta contra el rey que 
adicionales a Suárez y a otros jesuitas, e incluso a Santo Tomás, tratando de argumentar en favor de una conspiración para matar al rey instigada por Roma y en contra de la inocencia de los cinco ejecutados, dadas las simpatías que su último testimonio había generado en algunos sectores de la población.

\section{IX \\ BELLOC Y SUÁREZ}

Hilaire Belloc, autor del ensayo "The Liberal Tradition", que nos sirvió para caracterizar los rasgos fundamentales del liberalismo decimonónico inglés y su particular encrucijada hacia finales de siglo, puede ser considerado como un radical de principios del siglo $\mathrm{XX}^{96}$. Además, dada su condición de católico, sentía gran admiración por la figura de Francisco Suárez, al que atribuía el origen de las teorías democráticas sobre el gobierno.

De acuerdo con G.K. Chesterton, que escribió una biografía de Cobbett y conocía bien a Belloc, éste último tenía "exactamente el aspecto que un campesino inglés debería tener" y era "un mejor retrato de Cobbett que el propio Cobbett" ${ }^{\prime 97}$. Las similitudes entre Belloc y Cobbett no terminan en su común amor por la campiña inglesa o determinadas semejanzas biográficas ${ }^{98}$. Belloc compartía con Cobbett la idea de una idílica "vieja Inglaterra" que fue

ha devenido en tirano a "su legítimo sucesor, si es católico" y aclara que el hecho de que el Papa condene a un rey por hereje "no habilita sin más a todos para castigarle". Suárez, Defensio Fidei, libro VI, cap. 4, 19; en López Atanes, Bustos, y Villena (2010, 216).

${ }^{96}$ Esta es la tesis principal de Mc Carthy (1978).

97 Pearce $(2015,178)$

98 Cobbett vivió en Surrey y Belloc en la cercana West Sussex (aunque falleció en un precario hospital en Surrey). Ambos se dedicaron al periodismo crítico con el poder mediante publicaciones independientes (Weekly Political Register en el caso de Cobbett, The Eye Witness - New Witness - G.K. Weekly- The Weekly Review en el de Belloc) que sacaron adelante con pocos medios y tuvieron buena aceptación. Como aspecto negativo también en común, ambos fueron acusados, generalmente a título póstumo y sobre todo con posterioridad a la Segunda Guerra Mundial, de anti-semitismo por el talante de algunos de sus escritos. Junto con las similitudes señaladas, es preciso destacar las diferencias de estilo, siendo, de acuerdo con John P. Mc Carthy, las ideas de Belloc "mucho más sistemáticas y razonadas frente a la impulsividad y brusquedad de Cobbett" (Mc Carthy, 1978, 322). 
lentamente socavada por el creciente poder de una oligarquía acaparadora, en un proceso que comenzó con la Reforma Protestante ${ }^{99}$.

Si bien en su ensayo "The Liberal Tradition" Belloc rinde tributo al pensamiento de otros miembros de la tradición liberal radical como Fox, Bright y Cobden, su verdadera inspiración a la hora de fundamentar su "ideal civil" basado en la libertad personal, la responsabilidad y el honor proviene de la figura de William Cobbett $^{100}$. En este ensayo destaca la idea de que la libertad individual solo estaría garantizada, según Belloc, mediante la posesión de medios propios de subsistencia, pues si estos medios dependiesen de otros, los intereses políticos de la persona podrían verse condicionados por sus necesidades económicas ${ }^{101}$.

En materia de filosofía política, Belloc da un papel preponderante a Francisco Suárez como pionero de la teorías democráticas sobre el gobierno, al afirmar que el tipo de historiador "anticlerical", en su inversión del orden de los acontecimientos históricos, consideró a los escritores no católicos del siglo XVII como "promotores del gobierno popular, los primeros en establecer claramente la metáfora del contrato en sociedad o los principios de autoridad comunal" pues, continúa diciendo Belloc, "no ha sabido que derivan del eminente Suárez"102.

Belloc, al igual que los hermanos Chesterton, igualmente católicos y adscritos al movimiento distributista, situó a Suárez en el origen de una filosofía política que combina una visión "moderna" del origen y la legitimidad del poder civil con unos principios propios de la filosofía clásica y cristiana que enfatizan el vínculo moral existente entre los miembros de la comunidad. Belloc encontró atractivas las tesis de Suárez pues se hallaban en ellas las bases de principios como el consentimiento o la representación ${ }^{103}$ y se trataba además, contra lo que solía y suele pensarse, de unas bases

\footnotetext{
99 Villis $(2006,27)$

100 Ibid.

101 Belloc $(1897,29)$

102 Belloc $(1951,21)$

103 "No association, specially no association of a political kind, had a right to command the obedience of its members unless those members each had a part in the government of that which they were to obey" (Belloc, 1897, 7).
} 
de origen católico enraizadas en la tradición de la filosofía clásica y cristiana.

Para los autores católicos que fueron precursores del distributismo, la filosofía política de Suárez representaba una alternativa frente al contractualismo social que, teniendo su fundamento en una filosofía escéptica, partía de la imposibilidad de objetivar el concepto del bien, percibiendo la sociedad como construcción artificial y mecánica de pactos para hacer compatibles los intereses de sus miembros, proporcionando paz a la comunidad. Suárez, en cambio, empleando el concepto clásico y cristiano del bien común, hizo compatible una visión orgánica de la sociedad, donde la convivencia parte de la idea del consentimiento e implica obligaciones morales naturales a la cosa (el gobierno de la comunidad) y mutuas, con la garantía de la libertad individual frente a los abusos del poder.

\section{$\mathrm{X}$ \\ CONCLUSIONES}

Hilaire Belloc, al término de su formación académica en Oxford, reivindicó la tradición de los liberales radicales ingleses de los siglos XVIII y XIX, en contra de la tendencia hacia el pragmatismo político que ya en su tiempo comenzaba a presentar el Partido Liberal. En su ensayo "la tradición liberal" resume los que considera principios fundamentales de esa tradición y los sintetiza en la defensa de un "ideal civil" de ciudadano libre, honorable y responsable como base de la comunidad. La tradición liberal a la que Belloc alude asienta sus bases en una filosofía política que enfatiza la libertad individual frente al poder de los gobernantes y la necesidad de representación y participación de éstos en los asuntos públicos. Pero al mismo tiempo, de acuerdo con el "ideal civil" descrito por Belloc, sitúa cuestiones como la moral o el honor por encima las necesidades prácticas del estado o de la nación.

La filosofía política de Suárez, que combina asimismo elementos que hacen referencia a la teoría del consentimiento con un fundamento moral en la línea de los filósofos clásicos, la patrística y los escolásticos y con una visión orgánica de la comunidad, tuvo 
difusión en la Inglaterra del siglo XVII, a pesar de los obstáculos para la publicación y lectura de sus obras. Pese a que Defensio Fidei trataba una cuestión local y fue origen de su famosa disputa con Jacobo I, fue De Legibus la obra más citada y analizada por autores ingleses. Robert Filmer y Roger Manwaring, desde visiones justificativas de la autoridad real, y Algernon Sidney, Robert Mason y John Pym, desde puntos de vista favorables a la limitación de dicha autoridad en favor de la del Parlamento, proporcionaron argumentos a partir de las ideas y obras del jesuita español. Si bien no existe constancia al respecto, probablemente ejerció también influencia en John Locke, pues fue con el cardenal Belarmino el principal antagonista citado por Robert Filmer, de cuya obra El Patriarca partió Locke para criticar las posturas absolutistas. La persecución religiosa hizo que la obra de Suárez, referencia de vital importancia en los debates políticos del convulso siglo XVII, acabara prácticamente en el olvido, salvo en los reducidos y proscritos ámbitos del catolicismo eclesial inglés.

A finales del XIX y principios del XX, la filosofía política de Suárez comenzó a recobrar cierto protagonismo en Inglaterra, siendo reivindicada en particular por autores católicos como Hilaire Belloc. Belloc poseía un conocimiento amplio de la obra de Suárez y lamentaba que los historiadores del siglo XIX considerasen que los elementos más avanzados de la filosofía política moderna provenían de autores protestantes, cuando en realidad, de acuerdo con Belloc, lo hacían del Doctor Eximio. El rasgo de la filosofía política de Suárez más apreciado por estos intelectuales católicos ingleses sería su combinación de una teoría de corte democrático tendente a garantizar los derechos de las personas frente a los abusos de los poderosos, con un fundamento moral objetivo, basado en los valores cristianos. El énfasis en la limitación del poder del gobierno de la comunidad y en el componente moral de las relaciones políticas entre los miembros de ésta y del gobierno hacia dichos miembros, son característica fundamentales de la teoría "suareciana", que están presentes a su vez en el liberalismo decimonónico. Dicho liberalismo, basado en valores morales y altos ideales, sería paulatinamente sustituido en el campo de la acción política por un liberalismo de carácter pragmático. 
A principios del siglo XX, el gobierno británico, como hiciera el alemán treinta años atrás, estableció, de la mano del "nuevo liberalismo", una serie de reformas sociales que, si bien temporalmente podían servir para atender situaciones de necesidad, en la práctica conferían al estado un nuevo papel frente a los ciudadanos. Los sistemas educativos y sociales, puestos al servicio de la maquinaria industrial y militar, permitieron incrementar la efectividad de las políticas expansivas. De este modo, el estado comenzaba a pasar de ser concebido como un mero objeto a convertirse en un sujeto omnipresente en la vida de los ciudadanos. Sin embargo, desde Inglaterra, algunas voces se alzaron contra este incipiente "estatalismo", en nombre de la tradición liberal e invocando una teoría política que partía de un concepto orgánico de la comunidad, sustentada sobre un vínculo moral entre sus miembros y que, hundiendo sus raíces en los filósofos clásicos, encontró su máximo esplendor bajo la figura del jesuita español Francisco Suárez.

\section{REFERENCIAS BIBLIOGRÁFICAS}

Belloc, H. (1897): “The liberal Tradition”, en Belloc, H. y otros (1897), Essays in liberalism by Six Oxford Men, Londres, Cassell and Company Ltd.

- (1951): Cómo aconteció la Reforma, Buenos Aires, Emecé Editores.

- (2005): Historia de Inglaterra, Buenos Aires, CS Ediciones.

Bosca, R. (2009): “Suárez y Rousseau”, en Cruz Cruz, J., ed. (2009) La gravitación moral de la ley según Francisco Suárez, Barañáin (Navarra), EUNSA.

Berns, L. (1987): “Thomas Hobbes”, en Strauss, L. y Copsey, J., eds., History of Political Philosophy, Chicago, The University of Chicago Press.

Chesterton, G.K. (1910): William Cobbett, Londres, Hodder and Stoughton.

Cobbet, W. (1819): Complete collection of State Trials, Vol. VII, Londres, T. C. Hansard.

- (1819b): Parliamentary History of England, Vols. II \& XXXIV, Londres, T. C. Hansard. 
- (2009): History of the Protestant Reformation in England and Ireland, Colección de cartas de William Cobbett, Edición digital. Ex-classics Project.

Cendejas Bueno, J. L. (2017): «Economics, chrematistics, oikos and polis in Aristotle and St. Thomas Aquinas». The Journal of Philosophical Economics: Reflections on Economic and Social Issues, 10, 2, pp. 5-46.

Fernández Álvarez, A. (2017): La escuela española de economía, Madrid, Unión Editorial.

Filmer, R. (1680): Patriarcha, Edición digital, The Online Library of Liberty.

Godwin, R.A. (1987): “John Locke”, en STRAUSS, L. y COPSEY, J., eds. (1987), History of Political Philosophy. Chicago. The University of Chicago Press.

Gómez Rivas, L. (2014): Historia del Pensamiento Económico, Ávila, Servicio de Publicaciones de la Universidad Católica de Ávila.

Grande, J. y Stevenson, J., Eds. (2016): William Cobbett, Romanticism and the Enlightenment: Contexts and Legacy, Nueva York, Routledge.

Hobbes, TH. (1965): Leviathan, Oxford, Oxford University Press.

López Atanes, F.J., Bustos, I., y Villena, P.M., eds. (2010): Suárez: una aproximación al tratado de las leyes y la defensa de la fe, Madrid, Unión Editorial.

Marañón, G. (1956): Ensayos liberales, Madrid, Espasa - Calpe.

Mc Carthy, J. (1978): Hilaire Belloc: Edwardian Radical, Indianapolis, Liberty Press.

Migliore, J. (2009): "Suárez en Inglaterra", en Cruz Cruz, J., ed., La gravitación moral de la ley según Francisco Suárez, Barañáin (Navarra), EUNSA.

Negro Pavón, D. (2008): La situación de las sociedades europeas, Madrid, Unión Editorial.

Pearce, J. (2015): Old Thunder: A Life of Hilaire Belloc, Charlotte (NC), Tan Books.

Schama, S. (2005): Auge y caída del imperio británico 1776-2000, traducción de Juan Rabasseda-Gascón, Barcelona, Editorial Crítica. 
Strauss, L. (1987): “Niccolo Machiavelli", en Strauss, L. y Copsey, J., eds., History of Political Philosophy, Chicago, The University of Chicago Press.

Suárez, F. (1918): Tratado de las leyes y de Dios legislador, (9 vols.), traducción de Jaime Torrubiano Ripoll, Madrid, Hijos de Reus.

Villis, T. (2006): Reaction and the Avant-Garde: The Revolt against a Liberal Democracy in Early Twentieth-Century Britain, Londres, Tauris Academic Studies.

Ward, L. (2004): The Politics of Liberty in England and Revolutionary America, Cambridge, Cambridge University Press. 
